\title{
A INCOMENSURABILIDADE E A "COMPATIBILIZACAO" DE TEORIAS
}

\author{
José Borges Neto \\ Universidade Federal do Paraná \\ RESUMO
}

Este texto pretende problematizar, à luz da noção de incomensurabilidade de Kuhn e de Feyerabend, as tentativas de "compatibillização" ("aproximação", "articulação") de teorias linguisticas distintas cada vez mais frequientes a partir da segunda metade dos anos 80 .

"Basta você substituir o vódica por uísque e o suco de tomate por limão e açúcar para transformar um BloodyMary num uisque-sauer."

Millôr Fernandes

\section{INTRODUUÇĀO}

Em trabalho apresentado durante a $40^{\mathrm{a}}$ Reuniāo Anual da SBPC (São Paulo, 1988) RAJAGOPALAN deplora a "desenfreada proliferação de aparatos teóricos" que tem como conseqüência a "crise institucional" da Lnguística.

"Em suma, a linguiistica, hoje, são muitas coisas, cujo único denominador comum talvez seja a luta sem trégua pela posse da disciplina. Enquanto no eixo vertical - ou se se permitir um trocadilho inócuo, no sentido 'paradigmático' observa-se uma espécie de 'síndrome de múltipla personalidade', no eixo horizontal - isto é, no eixo sintagmático - podemos diagnosticar um estranho sumiço de identidade, de definição, face às disciplinas conexas."

(RAJAGOPALAN, 1988, p. 1)

A questão da proliferaçāo é abordada por RAJAGOPALAN a partir do reconhecimento de que há "motivação ideológica por trás da construção de teorias" - posição com a qual concordo integralmente e que já abordei em trabalhos ante- 
riores $^{1}$ - mas deixa transparecer seu desejo de uma teoria lingüistica unificada. Para RAJAGOPALAN, a existência de muitas teorias linguiisticas concorrentes cria um "impasse" que leva à "crise" e a única saída do impasse é a "re-aproximação entre as diversas correntes" com vistas à obtenção do paradigma único².

"[a crise institucional da lingüistica] se deve, entre outros fatores, à ausência de um único paradigma que funcione como força centripeta, que ofereça um conjunto de postulados gerais dentro do qual se possa enquadrar uma parcela significativa de pesquisa linguiistica em andamento."

(RAJAGOPALAN, 1988, $p_{\text {q }}$ )

Essa "re-aproximação" não é entendida como uma tarefa de fácil realização: RAJAGOPALAN propõe que se busquem inicialmente "canais de comunicação" entre as teorias e que se estabeleçam alguns parâmetros a partir dos quais essa "convivência" possa ser regulada.

A proposta de RAJAGOPALAN coloca alguns problemas interessantes para a Epistemologia da Linguística. Identificar "parâmetros dentro dos quais se possa pensar tal aproximação" equivale a responder à seguinte questão:

(1) Em que condiçōes é possivel "aproximar" teorias linguiísticas?

Como o leitor-lingüista já deve ter percebido, a questão (1) pressupōe outra questão, que lhe é anterior e com a qual a Epistemologia da Linguiistica terá que se ver. Em outras palavras, (2) é a verdadeira questão:

(2) E possivel "aproximar" teorias lingüisticas distintas?

Não creio que se possam dar, no momento, respostas definitivas à questão (2). Muito trabalho histórico e muito trabalho empírico sobre tentativas de "aproximação" deverá ser feito. Podemos, no entanto, aproveitar a experiência de filósofos e historiadores da ciência que já se debruçaram sobre questōes semelhantes em outras áreas do conhecimento científico e, à luz de seus resultados, estudar casos concretos de nossa ciência.

1 Ver BORGES NETO (1985 e 18B7). Para mim - e. crelo. para Rajagopalan também - o termo ideologia signifiea "sistema de ldcias". "concepçāo". de forma que tanto a poslçáo que ve "motivação ideolóslca" nas teorlas quanto a posiç̄o contrária sño fruto de Ideologias distintas no que tanse so funcionamento da ciéncla.

2 Ouso ver no trabalho de Rajasopalan a influencia da lestura do livo de HawkINO (1988). onde encontramos ua relato do esforco fefto pela Fisica. durante os últimos anos, nara unifiear a Teoria da Relatividade e a Teorla Quántica. Confesso estranhar profundamente a proposta de Rajagopalan - uma proposta "apolnea" vinde de um "dionialaco" explicito. 
Este é o objetivo deste trabalho. Tomando como referencial teórico os trabalhos de KUHN e de FEYERABEND estudaremos a "aproximação" entre a Sociolinguística (de fato, a teoria sociolingüística conhecida como Teoria da Variaçāo e da Mudança) e a Gramática Gerativa proposta na Sociolingüistica Paramétrica de Fernando TARALLO.

\section{A INCOMENSURABILIDADE}

A noção de incomensurabilidade surge no quadro de uma epistemologia que encara a teoria científica como algo mais do que um modo de descrever uma realidade que existe além e independentemente dela.

Esta noção não terá lugar numa epistemologia que pretenda construir "uma ciência livre de qualquer visão de mundo"3, uma ciência puramente objetiva e racional, como é o caso da epistemologia positiva ou neo-positivista ${ }^{4}$.

Por outro lado, qualquer epistemologia que entenda a ciência como uma atividade humana de reconstrução da realidade, qualquer epistemologia que encare as teorias cientificas como modos particulares, icleológicos, de ver a realidacie, necessariamente se verá às voltas com a noção de incomensurabilidade.

Eu estou convencido - e creio que RAJAGOPALAN também - de que a ciência constrói o seu objeto, de que as teorias implicam uma metafísica e de que a racionalidade e a objetividade da ciência são, em grande parte, uma mera ilusāo. As teorias científicas em geral, e as teorias lingüisticas em particular. são ideologicamente motivadas.

A noção de incomensurabilidade surge inicialmente em KUHN (1962) como uma noção ligada às mudanças de Gestait que acompanham as revoluçōes científicas.

"... as mudanças de paradigmas realmente levam os cientistas a ver o mundo definido por seus compromissos de pesquisa de uma maneira diferente. $\mathrm{Na}$ medida em que seu único acesso a esse mundo đá-se através do que vêem e fazem, podemos ser tentados a dizer que, após uma revolução, os cientistas reagem a um mundo diferente."

(KUHN, 1962, p. 146))

3 Palayras de Otto Neurath, referindo-se so Circulo de Vlena (ver NeuraTH, 1050b: 287 .

4 Ver or textos constantes de AYER (comp.) 1050. cspecialmente os textos III. IV. $V$ e IX. alèm do ensalo introdutórlo. 
Para KUHN, os 'mundos' separados por uma revoluçāo cientifica são incomensuráveis entre si.

"La comparación punto por punto de dos teorias consecutivas exige un lenguaje al que puedan traducirse sin pérdidas ni cambios como mínimo las consequencias empíricas de ambas. ... [muitos filósofos] continúan suponiendo que las teorias puedan compararse recurriendo a un vocabulario básico que esté compuesto totalmente por palabras asociadas a la naturaleza de un modo que sea noproblemático $\mathrm{y}$, en la medida necesaria, independiente de la teoría. (...) Feyerabend y yo hemos arguiido extensamente que no se dispone de ningún vocabulario de este tipo. En el paso de una teoría a la siguiente las palabras cambian sus significados o sus condiciones de aplicabilidad por vias sutiles. Aunque la mayoria de los signos son los mismos antes y después de una revolución por ejemplo, fuerza, masa, elemento, compuestos, célula - el modo en que algunos de ellos se asocian a la naturaleza ha cambiado de alguna manera. Decimos asi que las teorias consecutivas son inconmensurables."

(KUHN, 1970, p. 435-436)

A incomensurabilidade entre as teorias encontra-se ligada à tese de WHORF', para quem as linguas naturais, além de instrumentos de descrição de eventos, são ainda modeladoras de eventos. Para KUHN e para FEYERABEND, as teorias cientificas, nesse particular, não se distinguem das línguas naturais. As concepçōes de realidade vinculadas às teorias são, freqüentemente, tão distintas entre si quanto as ideologias subjacentes às culturas e assim como a língua, de certa forma, representa a ideologia da comunidade que a fala, a teoria veicula a concepção de realidade da comunidade científica que tem sua pesquisa orientada por ela. Em outras palavras, as teorias, como as línguas, não não neutras.

As comparações entre teorias distintas e a tradução de uma teoria a outra sāo possiveis, do mesmo modo que as traduções e as comparações entre as línguas naturais são possiveis. $O$ que se nega é a objetividade e a racionalidade das comparações e traduções ${ }^{6}$.

5 Ver Whort 1956 .

6 Todos sabemos que as traducies de uma lingua natural a outra. embora possirels. sempre enecrram alquma vlolencia contrs um dos idlomas: "Tradutore, tradittore". 
"Claro está, alguma forma de comparação é sempre possivel (por exemplo, uma teoria física poderá soar mais melodiosa do que outra, quando apresentada em voz alta, com o acompanhamento de um violão). Coloquemos, porém, regras especificas para o processo de comparação, tais como as regras de lógica, aplicadas à relação das classes de conteúdo, e depararemos com exceçōes, restrições indevidas, e seremos forçados, a cada momento, a sair do embaraço através de evasivas." (FEYERABEND, 1977, p. 358)

Fica claro que qualquer proposta de "aproximação" de teorias distintas ou retoma os postulados neo-positivistas ${ }^{7}$ ou encontra na questão da incomensurabilidade uma bar. reira formidável.

\section{A SOCIOLINGUISTICA PARAMETRICA}

Nossa primeira tarefa deveria ser a apresentação do conteúdo da proposta de TARALLO. Nāo o podemos fazer, entretanto, sem um certo trabalho prévio de exegese.

No resumo que antecede seu texto de 1987, TARALLO afirma:

"O ensaio procura demonstrar a compatibilidade entre as análises propostas pelo paradigma laboviano e pelo quadro teórico chomskiano."

(TARALLO, 1987, p. 51)

Ora, "demonstrar a compatibilidade" entre dois paradigmas, ou teorias, pode significar uma porção de coisas: demonstrar que as "motivaçōes ideológicas" das duas teorias são as mesmas; demonstrar que os procedimentos metodológicos são os mesmos; demonstrar que elas são variantes notacionais; demonstrar que é possível reduzir uma teoria à outra; demonstrar que seus objetos são complementares, etc. Precisamos de outras indicações de TARALLO que eliminem a vagueza de seus propósitos e esclareçam a proposta. Observe-se a seguinte passagem:

7 A "aproximaçio" entre a proposta de Rajagopalan e o programa do Cireulo de Viena pode ser percebida na sezulate passagem (troque-se "Clencla Unificada" por "Lineulstien Unlfleada"):

"Fa ripido nroaresso de la obra del Circulo de Viena muestra que cl trabajo colectivo planeado, dedicado en eite caso a la estructuración de la Ciencin Unifieada. ie halla en constante desnrollo. Cuanto menos tlemno sea necesarjo dedicar a la ellminación de antiguos errores $y$ cuanto más podamos ocuparnos en la formulaclón de las interconexiones de las clenclas, tanto más rapidamente y con mejor exito lograremos dichs construcción."

(Neurath. 1959a: 214) 
"Evidentemente, os pressupostos teóricos e os procedimentos metodológicos de um e de outro modelo são radicalmente opostos: nāo se trata pois de romper fronteiras e confundir domínios no sentido de 'parametrizar' (ou de eliminar) diferença, mas, sobretudo, de enfatizar a complementaridade entre os modelos naquilo que eles permitem (ou permitirem) compatibilizar resultados em relação àquelas questōes levantadas por Borer de um lado, e por Weinreich, Labov e Herzog, de outro, resultados esses que estāo muito mais próximos do que normalmente se pensa, se aceita e/ou se pensa aceitar."

(TARALLO, 1987, p. 55)

Creio que agora podemos avançar um pouco: algumas das alternativas que apontamos acima devem ser recusadas. "Demonstrar a compatibilidade" não significa demonstrar que as "motivações ideológicas" (=pressupostos teóricos) ou os procedimentos metodológicos são os mesmos. A afirmação de que "não se trata de romper fronteiras e confundir domínios" impede que entendamos a "compatibilizaçāo" como redução de uma teoria à outra e, com alguma boa vontade, impede que consideremos tratar-se de tradução. A afirmação de que os modelos "permitem ... compatibilizar resultados" leva a crer que Tarallho considera comensuráveis as duas teorias e a afirmaçāo de que se trata de "enfatizar a complementaridade entre os modelos" nos dá a indicação de que o pretendido no texto é demonstrar que as duas teorias são complementares ${ }^{8}$.

Mas o trabalho de exegese ainda nāo acabou. Precisamos entender o que significa dizer de duas teorias que elas são "complementares".

\subsection{TEORIAS COMPLEMENTARES}

Dizer que duas teorias sāo complementares pode significar que as duas teorias têm dominios diferentes, isto é, a "regiāo" do objeto estudada por uma teoria não é a mesma "região" estudada pela outra. Duas teorias seriam "complementares" nesse sentido quando tivessem por objeto "componentes" distintos da linguagem: uma teoria, por exemplo,

- Embora Tarallo só afirme que clas sīo complementares em alouns pontos c nåo dica que se trata de demonstrar a complementariedade, apenas de enfatizíla, que c. obviamente. um termo multo mals fraco. 
estudaria os fenômenos fonológicos enquanto a outra estudaria os fenômenos sintáticos.

Poderiamos supor que TARALLO estivesse tentando demonstrar que a Sociolinguiistica e a Gramática Gerativa tratam de aspectos diferentes, de "componentes" diferentes, do objeto e que sua proposta consistiria no estabelecimento de "pontes" que permitissem a passagem sem traumas, ou com poucos traumas, de uma a outra "região" do objeto.

Observando os casos tratados por TARALLO, e conhecendo as análises produzidas pelas duas teorias, podemos facilmente perceber que não é esta a concepçāo de "complementaridade" que está em jogo. Mesmo que quiséssemos dizer que a Gramática Gerativa estuda os fenômenos da competência enquanto a Sociolinguíistica estuda o desempenho, encontrariamos a resistência apaixonada dos sociolinguiistas, para quem a distinção competência/desempenho carece de sentido ${ }^{9}$.

O mais provável é que estejamos diante de uma nova versão do que FEYERABEND chama de Teoria do QueijoSuiço.

"Toda cosmologia (toda linguagem, todo modo de percepção) apresenta apreciáveis lacunas que podem ser preenchidas, permanecendo inalterado tudo o mais." (FEYERABEND, 1977, p. 393)

Uma das teorias em questāo - a Gramática Gerativa, por exemplo - daria uma descrição (ou explicação) do objeto de estudo. Como a realidade é sempre muito complexa ${ }^{10}$, inúmeros fatos permaneceriam sem descrição (ou explicação). Ai entraria a Sociolinguiistica, como uma teoria ancilar, para "preencher as lacunas" do tratamento gerativo. Da união ("aproximação", "compatibilização") das duas teorias obteriamos uma descrição mais completa (mais perfeita, mais interessante) do objeto. No caso em questão, não se trataria de uma das teorias apresentar lacunas e a outra simplesmente vir a preenchê-las; trata-se de duas teorias "queijos-suiços" que, simultaneamente, preenchem as lacunas uma da outra, sem perderem suas identidades. Em outras palavras, a Gramática Gerativa tem suas lacunas pre-

9 'I am not sure whether this is a useful distinction in the cong run', (Labov 1069: 759, citado apud Dittmar 1976: 141), A proposta de Ccdereren e Bankolf (1974). por outro lado. recupera, no quadro da Sociolingiústica, a dístinço competencla/desempenho, o que comprova que a "complementaridade" entrc as duas teorias nగ̌o reside ncsta distinçīo.

10 "A realidade é sempre mais ou menos do que nós queremos" fá dizia Fernando Pessaa (sob o heterónimo Ricardo Reis). 
enchidas pelas análises sociolinguiisticas, a Sociolingüistica tem suas lacunas preenchidas pelas análises gerativas e, nāo obstante, a Gramática Gerativa e a Sociolingiística permanecem exatamente como estavam (salvo pelo fato de não apresentarem mais lacunas) antes da "compatibilização".

$E$ este o sentido que TARALLO empresta ao termo "complementaridade" em seus trabalhos. $E$ não só em TARALLO, mas em outros autores, todos ligados à sociolinguiistica, conseguimos perceber a perspectiva do "queijo-suiço". Vejamos dois deles.

"Vamos olhar o problema, agora, do lado da Sociolinguística. Posso estar profundamente errado no que vou dizer aqui mas me parece que a inclusāo de fatores não-estruturais nas descriçōes gramaticais relaxou nossa atençāo quanto ao papel dos fatores estruturais nessas mesmas descriçöes."

(OLIVEIRA, 1986, p. 88)

O que, de certa forma, OLIVEIRA está querendo dizer é que há, na Sociolinguiistica, uma lacuna (uma "falha") os fatores estruturais - e que é preciso preenchê-la. Para eliminar essa "falha" são necessárias descrições de fatos estruturais e é mais fácil e econômico usar as descrições já existentes, produzidas no quadro de uma teoria que tenha desenvolvido instrumental adequado para isso - o que não é o caso da Sociolinguística ${ }^{22}$ - do que criar todo um aparato descritivo novo. A Gramática Gerativa está justamente produzindo descrições de estruturas gramaticais em grande número. Basta que o sociolinguiista preste mais atenção aos resultados das análises gerativistas para que haja grandes possibilidades de que as lacunas de sua teoria sejam preenchidas.

"Na constatação e explicação da variação, de sua estabilizaçāo e/ou de seu processo de desenvolvimento rumo à mudança, levando-se em conta tanto

11 Numa versa mais recente do texto (Ollveirs 1987n, esta passazem ć substancia]mente alterada. $O$ ponto em questio. no entanto, ndo só permanece como até permite que identiflazuemos com malor clareza a perspectra do "cuelfo-sulco":

"nao estariam as práttcas sociolinguistleas Incorrendo. por rezes, num tipo de falha. ra medida em nuc nảo exploramos ed profundidade os annectos cstruturals dos casos detectados como casos de vartacto?" (p. 21 - o grifo é meu)

12 Como facllmente podemos perceber pereorrendo os trabalhos sociolinguistleos. os dados sño descritos usando a notacho da Gramatles Gerativa, do estruturalismo ou de alguma outra teoris. Tomo-so como exempio BANKOFF \& TARALLO (1987) c procure-se ver de onde saem os instrumentos de descrlcāo (anáfcra, cláusula relatlva, pronome. COMP (lementizador) etc.) $e$ se há diferencas malores quanto i notacao utilizads entra cste trabalho e as ansilses cerativas convencionais. 
as motivações lingüísticas quanto as extralinguiisticas - ou sociais - , reside, sem dúvida, a grande contribuição da ciência lingiiística social - a So. ciolingüística - para o acervo do conhecimento sobre a linguagem humana articulada. Parece óbvio que o estudo do fenômeno linguagem não se poderia resumir à descrição e explanação da competência lingüistica - tal como a define Chomsky -, por mais completos, exaustivos e convincentes que sejam tais procedimentos." (ALMEIDA, 1989, p. 86 o grifo é meu).

O que esta passagem nos mostra é que, para o sociolingüista ${ }^{13}$, a Gramática Gerativa tambèm apresenta lacunas (ou "falhas"): falta-lhe um tratamento para a variação e a mudança e falta-lhe o encaixamento do linguístico no social. Acredito que é desnecessário acrescentar que para ALMEIDA é justamente a Sociolinguística que tem condiçōes de "com. pletar" a Gramática Gerativa.

A consideração das teorias linguíísticas como "queijossuiços" é o que está por trás do Zelig de TARALLO"1: seu "camaleão-lingüista" é alguém que, consciente das lacunas das teorias, não pode (não consegue ou nāo quer) assumir compromissos mais fortes com qualquer uma delas. Não passa pela cabeça de Zelig a possibilidade de "superar" duas teorias incompatíveis criando uma terceira. Zelig entende as teorias como "queijos-suiços" e o mais fácil é simplesmente justapô-las como se fossem peças de um jogo de encaixes.

Creio que já avançamos bastante na direção de um entendimento mais profundo da proposta de Tarallo. Há ainda, no entanto, alguns pontos a serem esclarecidos.

\subsection{TEORIAS INCOMENSURÁVEIS.}

Toda teoria supõe um ponto de vista (um modo de representação, um sistema de referências, um cosmos) cujos elementos (conceitos, "fatos", "dados", componentes) surgem de acordo com certos princíplos de construção ${ }^{15}$. Estes princípios de construção vão permitir que a teoria diga ou descubra certas coisas e vāo impedir que diga ou descubra

13 Bempre cabe percuntar o qua o gerstivista pense disso tudo. Wo crelo que haja gerativístas (nho-dissidentes) quelxando-se de que sua teorla nao dí conta do encalxamento soclal da lincuarem ou de que sus teorla náo permite a tratamento da varlacha c da mudanca. Săo os soclolinglitstas que vêm lacunas na Gramálica Gerativa.

14 Ver Tarallo (1988в). Nāo you me alongar sobre esta proposta de Tarallo porque fí o $\mathrm{flz} \mathrm{em}$ outro lugat (ver BORGE NETO \& MULLER 1887).

15 Saussure (1916: 15) J6 dizia: "O ponto de vista constról o objeto". 
outras coisas. Em outras palavras, há conceitos ("fatos", "dados") que não podem ser ditos ou descobertos sem que os princípios de construçāo sejam violados ${ }^{11}$. Por exemplo, o behaviorismo skinneriano pode dizer muitas coisas e descobrir muitos fatos mas, certamente, não pode descobrir "fatos mentais", nem se referir a eles, sem violar seus principios de construção. Sustar (recusar, falsear, negar, violar) os princípios de construção significa sustar todos os "fatos" e todos os conceitos da teoria.

Para sabermos se duas teorias são ou nāo incomensuráveis, basta tomarmos alguns fatos (ou conceitos) construidos em um delas e vermos se eles sustam ou não os principios de construção da outra: se sustarem, as duas teorias sāo incomensuráveis.

Poderíamos tentar discutir a (in)comensurabilidade das duas teorias que vimos analisando por meio de uma análise detalhada dos principios de construção de uma e de outra. Vamos, no entanto, discutir esta questão a partir de um exemplo. tabela:

Tomemos emprestada de MILROY (1980) a seguinte

\begin{tabular}{lcccccccc}
\hline & 1 & 2 & 3 & 4 & 5 & 6 & 7 & 8 \\
Variables & $(\mathrm{ai})$ & $(\mathrm{a})$ & $(\mathrm{l})$ & $\left(\wedge^{2}\right)$ & $(\mathrm{th})$ & $\begin{array}{c}6 \\
\left(\Lambda^{2}\right)\end{array}$ & $\begin{array}{c}\left(\varepsilon^{1}\right) \\
\left(\varepsilon^{2}\right)\end{array}$ \\
\hline Hannah McK & 1.4 & 1.05 & 1.2 & 0 & 0 & 0 & 66.7 & 25.00 \\
Paula C & 2.4 & 2.63 & 2.5 & 9 & 58.34 & 70.46 & 100 & 47.83
\end{tabular}

Two speakers' seores for eight phonological variables. 1-3 are inclex scores; 4-8 represent percentages. A higher score incticates a relatively rlose approxinntion to vernacular norms.

(MILROY, 1980, p. 131 - Table 5.4)

Segundo MILROY, a tabela mostra claramente que Paula aproxima-se mais das normas linguiisticas do vernáculo do que Hanna. As características sociais (idade, sexo, classe etc.) de ambas são muito semelhantes e, no entanto, há uma diferença sistemática, nas oito variáveis estudadas, entre a norma do vernáculo e a fala de cada uma das informantes. Para explicar essa consistência, MILROY propōe uma hipótese:

$$
\begin{aligned}
& \text { "closeness to vernacular speech norms correlates } \\
& \text { positively with the level of integration of the }
\end{aligned}
$$

16 Slgo bem le perto, nesta exposicño. FEYERABEND 11977: 3961. 
individual into local community networks." (MILROY, 1980, p. 133-134).

A hipótese de MILROY é corroborada pela constatação de que Paula é mais integrada do que Hanna na comunidade em que ambas vivem, isto é, as relações de Paula com outros membros da comunidade (vizinhos, colegas de trabalho etc.) e sua presença em grupos informais são mais intensas do que as de Hanna.

Vejamos agora que elementos estão em jogo neste exemplo. Comecemos com os dados que MILROY usa:

D.1.: os "scores" dos falantes em relação às variáveis fonológicas;

D.2.: o complexo de relaçōes entre os indivíduos que compõem a comunidade em que vivem Paula e Hanna;

D.3.: uma descrição, independente, do vernáculo.

E fácil ver que esses dados supōem um certo número de conceitos teóricos que, em consequiência, também estão sendo usados por MILROY. Fiquemos com os mais evidentes:

\section{C.1.: conceito de variável:}

"A sociolinguistic variable is a linguistic element... which co-varies not only with other linguistic elements, but also with a number of extra-linguistic independent variables such as social class, age, sex, ethnic group or contextual style."

(MILROY, 1980, p. 10).

C.2. conceito de vernáculo:

“the speaker's least overtly careful style."17

(MIROY, 1980, p. 12).

C.3.: conceito de comunidade:

"Membership of a group labelled 'lower-middleclass' does not necessarily form an important part of a person's definition of his social identity. Yet smaller-scale categories are available which reflect the fact that are social units to which people feel

17 E o estllo de fala que Labov chamn de estila B (ver Labov 1972): cap. 3. 
they belong and which are less abstract than social classes. For this smaller-scale, more concrete, unit we reserve the term community used in a specific, technical sense."

(MILROY, 1980, p. 14).

\section{C.4.: conceito de rede social ("social network"):}

"Network analysis, in a broad sense, is the study of the relations that exist in an ongoing system. When applied to social systems, network analysis is a structural strategy which is primarily concerned with relations among the individuals in any group."

(BORTONI, RICARDO, 1985, p. 69).

Além desses dados e desses conceitos, MILROY precisa de um instrumento de medida, que permita estabelecer, objetivamente, a distância entre a fala do individuo e o vernáculo, e de uma hipótese que preveja a correlação entre os resultados das medidas e a integração dos indivíduos na rede de relações sociais da comunidade.

A partir dos conceitos MILROY estabelece os dados: os conceitos pertencem à teoria utilizada e dizem que tipo de fenômeno observar e que tipo de resultado buscar tirar dos fenômenos observados.

De posse dos dados, MILROY busca explicá-los, isto é, deduzi-los de uma hipótese. A hipótese de que dispōe deter. mina que a variação é determinada por fatores extra-lingüisticos do tipo sexo, idade, classe social, etc. Como MILROY é capaz de perceber nos dados fenômenos sistemáticos que fogem das possibilidades de explicação da hipótese disponivel, MILROY cria nova hipótese. Nesse processo de criação da hipótese, MILROY estabelece, inicialmente, dois fatos:

F.1.: a fala de Paula é menos distante do vernáculo do que a fala de Hanna;

F.2.: Paula é mais integrada do que Hanna na comunidade em que ambas vivem.

A relação entre os dois fatos cria uma hipótese local, que estabelece correlação entre a distância relativa fala-de-Paula vernáculo e fala-de-Hanna/vernáculo e a integraçāo de Paula e Hanna na comunidade. Essa hipótese local é generalizada numa hipótese geral que diria algo como: As distâncias relativas entre as falas individuais e o vernáculo se correlacionam com as posiçōes relativas dos indivíduos na rede de relaçōes sociais de sua comunidade. 
Todos os fatos estabelecidos dai para a frente, ou seja, todos os fatos sobre as distâncias entre as falas dos membros da comunidade e o vernáculo e sobre os diferentes niveis de integração dos individuos na comunidade, deverão ser deduzidos da nova hipótese geral.

Feita a análise do exemplo, podemos passar à questão que nos interessa: é possível dizer, no quadro da Gramática Gerativa, o que MILROY diz sobre a fala de Paula e de Hanna? E possível, no quadro da Gramática Gerativa, usar os dados que MILROY usa? usar os conceitos que MILROY usa? descobrir os fatos que MILROY descobre? postular a hipótese que MILROY postula?

Qualquer pessoa que tenha um conhecimento pouco mais que superficial de Gramática Gerativa só poderá responder a essas perguntas com um claro e sonoro NĀO.

Não é necessário multiplicarmos os exemplos. A conclu. são a que chegaremos com a análise de outros exemplos não deverá ser diferente da conclusão a que chegamos com a análise deste: não é possivel encontrar (dizer, descobrir, usar) conceitos (fatos, construtos, correlaçōes, hipóteses) de uma teoria na outra ${ }^{18}$.

Talvez se pudesse levantar a seguinte objeção: embora não se possa encontrar conceitos da sociolingtuística na Gra. mática Gerativa, é possivel encontrar conceitos da Gramática Gerativa na Sociolinguística, o que confirmaria o dogmatismo (o "não-camaleão") do gerativista. Submeterei esta objeção a uma análise mais demorada na próxima seção deste texto.

Ignorando, provisoriamente, a objeção, assumirei a conclusão de que elementos da Sociolingüística não aparecem na Gramática Gerativa e vice-versa. Isto se dá por mero acidente ou cada teoria apresenta propriedades estruturais que impedem a coexistência de elementos de uma e de outra teoria? A resposta é óbvia. Há propriedades estruturais - os princípios de construção - que impedem essa coexistência. A Gramática Gerativa e a Sociolingüística são teorias incomensuráveis e, em consequiência, não faz nenhum sentido tentar "aproximá-las" ou "compatibilizá-las".

"Cada teoría es, en sí misma, un todo en el que el análisis en elementos o componentes disjuntos resulta... irrelevante. Esto se debe a que todos los

18 Esta aftrmacrio é ompirica e, enquanto tal, poderá ser contestada. Lcve-se em conta, no entanto, que cu năo estou falando de termos - termos comuns as dua. teorfa; há mustos - mas de conceitos ifatos, dados, hipóteses cte.) o termo IIngua, por exemplo, apsrece nas duas teorias, mas com sentldos radicalment distinto:. Para usar a terminologia de Chomsks, a Boclollngulfstica atém-se ì E-lingua enquanto a Gramática Gerativa toma como objeto a i.lingua (ver CHOMEKY 1986). 
términos de una teoria semejante sólo puedan alcanzar su significado y sus criterios de objetividad y verdad en el contexto total dado por dicha teoria."

(BOHM, 1979, p. 423).

É fácil ver que os objetos da Gramática Gerativa e da Sociolinguística sāo distintos: o objeto da Gramática Gerativa é a "gramática universal", entendida como "a characterization of the genetically determined language faculty" (Cf. CHOMSKY, 1986), enquanto o objeto da Sociolinguística é "the grammar of the speech community: the system of communication used in social interaction" (Cf. LABOV, 1982). Como os dados nāo sāo mais do que manifestações do objeto, como os conceitos são representações de elementos atribuídos ao objeto, como as hipóteses são sempre hipóteses sobre o objeto ou sobre seus elementos, nāo há como "romper fronteiras e confundir domínios".

Do mesmo modo, nāo faz nenhum sentido pretender que uma teoria desempenhe tarefas para as quais não foi construída. Não se pode exigir que a Gramática Gerativa dê conta da variação e da mudança lingüistica ou que a Sociolingüística dê conta da gramática universal presente na mente/cérebro dos falantes como herança genética. Cada teoria tem seu objeto e seus objetivos e, a partir dai, constrói todo seu aparato teórico.

"Só há uma tarefa que podemos legitimamente exigir que uma teoria desempenhe: deverá proporcionar-nos correta visão do mundo, ou seja, da totalidade de fatos, tal como constituidos por seus próprios conceitos básicos."

(FEYERABEND, 1977, p. 411).

\subsection{A SOCIOLINGUUISTICA PARAMÉTRICA, FINALMENTE.}

Já temos, enfim, condiçōes de esclarecer, analisar e cri. ticar a proposta de TARALLO. Vamos fazê-lo, novamente, a partir da análise de exemplo.

Para propor a "sociolingüística paramétrica", TARALLO usa, entre outros, o exemplo do funcionamento da inversão livre de sujeito em português, espanhol e francês ${ }^{19}$.

A Gramática Gerativa propōe que as línguas sejam di. vididas em dois grandes grupos a partir do parâmetro pro.

19 Ver Tarallo 1987: 69 e s5. 
drop (ou Parâmetro do sujeito nulo) e define esse parâmetro a partir de um conjunto de propriedades, uma das quais é a inversão livre de sujeito. $O$ francês é normalmente caracterizado como uma língua não pro-drop, enquanto o português e o espanhol seriam pro־drop.

“. . o francês não se caracteriza por ser pro-drop. Ou seja, a impossibilidade de sujeito nulo em francês prevê também a não-inversão livre de sujeito. Contrariamente, e por definição do parâmetro sintático, o espanhol e o português, ao apresentarem sujeitos nulos, prevêem a inversão livre de sujeito". (TARALLO, 1987, p. 70).

Nas três línguas, no entanto, apesar da parametrização distinta, a inversão de sujeito se dá, e de forma muito seme. lhante. Em nenhuma das três línguas a inversão é livre, mas sempre condicionada por fatores sintáticos. Esses fatores, entretanto, têm comportamentos distintos nas três línguas, em desobediência aos limites dados pelo parâmetro pro-drop.

Os fatores de condicionamento são:

a) a inversāo do sujeito é mais fácil com verbos intransitivos (nas três linguas);

b) a inversão é condicionada pela presença de um "gatilho" em posição pré-verbal (em francês e espanhol);

c) a inversão é restringida pelo "peso" do sintagma nominal sujeito, de forma que quanto maior o "peso", mais difícil a inversão (em português e francês).

Diante desses fatos, TARALLO pergunta:

"será o francês um sistema tão pro-drop quanto o espanhol e o português? Serão o espanhol e o português menos pro-drop do que se pensa?" (TARALLO, 1987, p. 74).

Segundo TARALLO, a noção de parâmetro procura resgatar, no quadro da Gramática Gerativa, a variação linguiís. tica inter-sistêmica e o que ele propõe é que se dê um passo a mais: que se traga a noção de parâmetro para o interior das línguas e, com ela, procure-se resolver a variação intrasistêmica. Como a variação intra-sistêmica é o "assunto" tradicional da Sociolingủística, o que obtemos com esse passo é uma Sociolingüistica Paramétrica.

"Ao 'parametrizarmos' as línguas do ponto-de-vista da teoria da variação e da mudança, estamos na 
realidade colocando os fatores condicionadores à aplicação de determinadas regras locais dentro de uma perspectiva 'paramétrica'."

(TARALLO, 1987, p. 75).

A proposta de TARALLO admite duas interpretaçōes: uma interpretação forte e outra fraca. A interpretação forte suporia a introdução da noção de parâmetro, tal qual cons. tituida no quadro da Gramática Gerativa, no conjunto de conceitos teóricos da Sociolinguíística. A interpretação fraca, por outro lado, suporia a criação, no quadro da Sociolinguisstica, de um conceito de parâmetro (homônimo do con. ceito da Gramática Gerativa). O texto de Tarallo não permite que se decida facilmente por uma ou outra interpretação: aparentemente, ele hesita entre as duas.

Consideremos, inicialmente e por hipótese, que TARALLO assume a interpretação forte. "Sociolinguiistica Paramétrica", nesta interpretação, deve significar a introdução da noção de parâmetro na Sociolingüística, sem que esta perca sua identidade.

Como vimos acima, as duas teorias são incomensuráveis, de forma que não há a possibilidade de conceitos de uma teoria aparecerem na outra sem que os principios de construção sejam violados. Há, no entanto, a possibilidade de ignorar a questão da incomensurabilidade adotando uma perspectiva instrumentalista frente às teorias lingüísticas.

Uma interpretação instrumentalista das teorias científicas as vê como instrumentos de descrição e classificação de "fatos" obtidos, objetivamente, por uma linguagem de observação independente de teorias. Se os "fatos" são sempre os mesmos - porque teoricamente neutros - não haverá problemas em comparar, avaliar empiricamente ou mesmo justapor teorias distintas que deles pretendam dar conta.

$\mathrm{Na}$ perspectiva instrumentalista as teorias são meras notações adequadas para o cálculo e para as previsões dos "fatos". Com isso, a meu ver, o instrumentalismo retira das teorias científicas o que elas têm de essencial, que é a visāo de mundo.

E fácil perceber a interpretação instrumentalista que as teorias linguiisticas recebem quando vemos o que Tarallo precisa fazer com a Sociolinguiística para que a noçāo de parâmetro caiba em suas análises.

"Se desconsiderarmos por um momento o compo. nente social da linguagem, tão presente nos estudos de variação e de mudança lingiísticas, veremos uma nítida relação entre as questões formuladas 
acima [questōes que BORER, enquanto gerativista, coloca para a teoria dos parâmetros] e alguns dos princípios estabelecidos pela Sociolingüística (variação e mudança) no texto clássico de Weinreich, Labov e Herzog."

(TARALLO, 1987, p. 54 - os grifos são meus).

A relaçāo de "complementaridade" entre Gramática Gerativa e Sociolinguiistica torna-se nitida "se desconsiderarmos... o componente social da linguagem", ou seja, se esvaziarmos a sociolinguística do que lhe é característico. Sem a perspectiva do social, sem a consideração do nāo-estrutural, a Sociolinguiistica deixa de ser uma teoria e passa a ser uma metodo. logia de análise de dados lingüisticos que só se distingue de outras metodologias pela atenção que presta às variações individuais de linguagem e pelo uso de instrumental estatístico.

A Gramática Gerativa, como vimos, não tem como aproveitar os resultados da pesquisa sociolinguiística. Na medida em que esses resultados referem-se à comunidade lingüística e nāo ao individuo, na medida em que esses resultados são obtidos sobre a linguagem entendida como produto e não sobre a linguagem entendida como um saber inato inscrito na mente/cérebro dos falantes, na medida em que esses resultados envolvem, de forma indissociável, o estrutural e o nãoestrutural, eles nāo têm lugar no "munđo" do gerativista. Se retirarmos o não-estrutural, se retirarmos o social dos dados, não teremos mais dados sociolingüisticos. $\mathrm{E}$ se, além disso, usarmos para a análise estrutural dos dados a notação desenvolvida pela Gramática Gerativa estaremos fazendo exatamente o que Tarallo quer evitar, e que considera um preconceito.

"Nossa maior intenção foi a desmistificação de alguns pré-conceitos (ou serão eles preconceitos?) correntes na linguiistica atual: 1 . que as análises de base empirista sociolingüistica têm por motivação primordial falsear as análises de modelos psicológicos [gramática gerativa]."

(TARALLO, 1986b, p. 20).

O gerativista sabe que os parâmetros, e suas propriedades acfinidoras, são propostos como hipóteses empíricas e que a testagem dessas hipóteses nos dados linguiisticos the dará "feedback" para mantê-las ou alterá-las. Ele sabe também que suas hipóteses, enquanto hipóteses sobre a Gramática Universal, devem valer para todas as línguas e para to- 
das as variações das línguas. Os dados das análises sociolingüisticas, então, podem ser interessantes para o gerativista, que deverá, no entanto, reinterpretá-los garantindo que nāo há determinaçōes de outros módulos da mente, além do módulo "linguagem", na sua realização.

A introdução da noção de parâmetro na Sociolinguiística, então, determinará ou que o conceito de parâmetro seja retirado de seu lugar próprio, e com isso descaracterizado, ou que a Sociolingüistica fique esvaziada do que lhe é essencial.

Passemos agora à interpretação fraca. Nesta interpretaçāo, o termo parâmetro deve ser entendido como um homónimo do parâmetro da Gramática Gerativa. Nāo se trata mais de emprestar um conceito mas de se construir, no quadro da Sociolinguística, um novo conceito que receberá o nome de parâmetro e que, na melhor das hipóteses, apenas permitirá uma relação analógica fraca com o conceito da Gramática Gerativa. Há passagens, no texto de TARALLO, que permitem essa interpretação.

"Os resultados obtidos por Poplack sobre a variação fonológica de (s) no espanhol portorriquenho apontam, pois, para a seguinte 'parametrização': o simples enfraquecimento de segmentos consonantais em variação é, via de regra, regido por fatores puramente estruturais, e, ao se iniciar o processo de apagamento, tais fatores estruturais começam a interagir com fatores de outra ordem, os funcionais. Tal 'parametrização' permite, ainda, uma terceira colocação (ou previsāo): no caso de um segmento que apresente mais de uma etapa de enfraquecimento (diferentemente, pois, de (s) que prevê somente uma: a aspiração), a força dos fatores funcionais poderia ser traçada à medida que os vários processos de enfraquecimento dirigem o segmento variável ao total apagamento. $E$ o que $P o-$ plack nos demonstra a partir de uma análise de (n)."

(TARALLO, 1987, p. 63).

O que temos nessa passagem é o levantamento dos fatores que regem um processo de muaança (o apagamento de (s) em espanhol portorriquenho). Essa mudança se dá em duas etapas: na primeira, a mudança é condicionada principalmente por fatores estruturais; na segunda, por fatores estruturais e funcionais.

TARALLO vai perceber que algo análogo acontece com o português e com o francês e vai propor que esses "passos" 
semelhantes no processo de mudança fonológica sejam tratados como parâmetros.

Para percebermos mais claramente como essa noção de parâmetro proposta por TARALLO não tem nada a ver com a noção da Gramática Gerativa, deixemos que BORER (bastante citada por Tarallo) nos diga o que são os parâmetros:

\begin{abstract}
"Em essência, dividir a GU [Gramática Universal] em princípios, de um lado, e parâmetros, de outro, implica num processo particular de aquisição da linguagem. Quando uma criança é exposta aos dados do meio (input data"), ela está equipada com dois tipos de mecanismo. Primeiro, ela tem disponível uma gramática construida sobre os principios universais. Segundo, com base nos dados do meio, a criança determina o vaior de um parâmetro particular. O conjunto das escolhas e sua natureza é pré-determinada: os dados do meio não introduzem mecanismos teóricos não existentes previamente ou uma escolha não especificada nos parâmetros da GU. Pelo contrário, eles permitem à criança escolher uma possibilidade particular dentre duas (ou mais) existentes."

(BORER, 1981, p. 11).
\end{abstract}

Trabalhando em cima de uma analogia com a genética, poderiamos dizer que os princípios universais equivalem ao genoma e que as gramáticas das línguas particulares equivalem às realizações particulares do genoma (os fenótipos). Todas as possibilidades de realização da gramática universal, sob a forma de gramáticas de linguas particulares, são de algum modo pré-determinadas e devem já estar inscritas na própria gramática universal.

A noção de parâmetro de TARALLO, por outro lado, não pode ser caracterizada como um "detalhamento de universal". TARALLO não parte de um universal e busca suas realizações particulares (se o fizesse seria simplesmente um gerativista), parte de particulares e, por indução, busca princípios cada vez mais universais. Seu parâmetro é uma generalização de particulares e aproxima-se muito mais dos universais implicacionais de Greenberg do que dos parâmetros da Gramática Gerativa.

Em suma, se entendermos a Sociolinguística Paramétrica na interpretação forte, estaremos diante de uma visão instrumentalista das teorias lingüísticas, que descaracteriza estas teorias retirando-lhes a essência. Se assumirmos a interpretação fraca estaremos diante do uso do termo parâmetro 
para designar algo que a meu ver não é muito distinto do universal implicacional de Greenberg. Em nenhuma das interpretaçōes estaremos diante da possibilidade de "aproximação dos contrários".

Em que sentido, entāo, a "parametrização" dos dados da variaçāo e da mudança permitiria uma aproximação entre a Sociolingüistica Paramétrica e a sintaxe paramétrica desenvolvida na Gramática Gerativa?

Quer me parecer que a única possibilidade se resume no seguinte: para Tarallo, a Gramática Gerativa, com a noçāo de parâmetro, inicia um movimento na direção do variável, do diferente. Os Universais não são mais, de certa forma, absoIutos, mas admitem inúmeras realizações distintas, ou seja, admitem "variaçāo". Se, num movimento antitético, a Sociolinguifstica deixar de se preocupar exclusivamente com o variável, se, para além do variável, passar a ver generalizações ("parâmetros"), podemos prever um momento em que o detalhamento da Gramática Gerativa se encontre com a generalização da Sociolingüística.

Voltando ao exemplo da inversão de sujeito, podemos ver que, segundo a concepção de TARALLO, ao parametrizar a sintaxe, a Gramática Gerativa desce um nivel no grau de abstração, aproximando-se do concreto. A Sociolingüística, isto é, os trabalhos de variação e mudança realizados sobre casos de inversão de sujeito em francês, espanhol e português, na medida em que são "parametrizados", sobem um degrau na direção do abstrato. Pode-se prever que a "abstraçāo" da Sociolinguíistica e a "concretização" da Gramática Gerativa aproximem "de forma lenta, gradual e segura" as duas teorias. Para TARALLO, tal "aproximação" não só é desejável, como é inevitável. Não fica clara, nos trabalhos de TARALLO, a vantagem que a Sociolingüistica teria com essa "aproximação", mas, para a Gramática Gerativa, a "aproximação" abriria a única saída para a avaliação empírica das hipóteses de parâmetros.

“somente uma leitura 'parametrizada', tal qual a propusemos, dos fatores condicionadores levantados pela teoria da variaçāo e da mudança garantirá, entre outras coisas, uma eventual redefiniçāo e um possivel realinhamento das propriedades previstas para determinado parâmetro sintático." (TARALLO, 1987, p. 75).

Parece claro que a proposta de TARALLO, nessa interpretação fraca, é, de novo, a teoria do "queijo-suiço" em ação. 
Não se trata, porém, de justapor teorias, mas de justificar resultados de teorias.

Ora, se as teorias são incomensuráveis, seus resultados também o serão. Os resultados (os "fatos" descobertos pela teoria) estão condicionados pelos princípios de construção tanto quanto os conceitos, as hipóteses, etc. Dessa forma, a incomensurabilidade "mata na casca" essa proposta de uma Sociolingüistica Paramétrica.

\section{CONCLUSĀO.}

Toda a análise que fizemos na parte 3 deste trabalho procurou mostrar que a busca de parâmetros que orientem a "convivência", as "re-aproximações", entre as teorias lingüisticas - tarefa proposta por RAJAGOPALAN - deverá necessariamente levar em consideração a natureza ideológica das teorias e, em consequiência, a possivel incomensurabilidade entre elas. Nem todas as "aproximações", no entanto, serão inviảveis. LABOV (1981), por exemplo, faz uma aproximação, aparentemente bem sucedida, entre os tratamentos dados à mudança lingüistica pelos Neogramáticos, de um lado, e pelos difusionistas, de outro. Trata-se, no entanto, não de duas teorias, como Sociolingüística e Gramática Gerativa, mas de duas hipóteses explicativas para os mesmos dados: as diferenças sāo mais metodológicas do que ideológicas. Neste caso, a incomensurabilidade está ausente e a "aproximação" é possivel. O sucesso eventual numa "aproximação" ou "compatibilização" não nos permite concluir que todas as aproxima. ções e compatibilizações são possíveis.

Não vejo porque se deva deplorar a proliferação de teorias, nem vejo a proliferaçāo como causa de "crise". Ao contrário. Em ciência, só se obtém o progresso quando há pontos de vista em conflito - a ciência só progride "pela discussāo critica de visões alternativas", como diz Feyerabend. A idéia de paradigma único, embora possa parecer atraente, significa o monopólio de um ponto de vista, de uma ideologia, e todo monopólio ideológico leva ao dogmatismo.

Não há porque temer a proliferação. Não há porque de sejar "aproximações" ou "compatibilizaçōes". Cađa teoria é uma estrada que assim como pode levar a alguma cidade, pode terminar num precipicio ou num fundo de vale. Cada teoria deve ser levada às suas últimas consequiências, sem "camaleonices", para que possamos saber da fertilidade de seu ponto de vista. Quem puder mais, chorará menos.

A Sociolingüística e, em especial a Teoria da Variação e da Mudança, tem o seu lugar, tem o seu interesse e a sua importância. Enquanto teoria da variação linguiística, enquan- 
to teoria da mudança linguística, enquanto teoria das relaçōes entre o linguiístico e o social, a contribuição da Sociolinguiística nāo pode ser desprezada. O mesmo acontece com a Gramática Gerativa. E impossivel ignorar o papel desta teoria se estivermos interessados na maior compreensão do funcionamento das línguas naturais. Aproximar essas duas teorias significa ou descaracterizá-las, jogando fora todo o acervo de conhecimentos que, cada qual a seu modo, acumularam, ou sonhar com uma utopia em que a ciência seja objetiva e racional, o mundo seja transparente e o cientista seja capaz de ver para além das aparências.

Se queremos sonhar com utopias, busquemos as "apro. ximações". Se, por outro lado, queremos nos engajar na atividade real da ciência, deixemos as teorias desenvolverem-se autonomamente, com todas as suas virtudes e limitações.

Não pretendo ser o dono da verdade. Nāo pretendo ter demonstrado "efetiva e cabalmente" nenhuma tese. Posso estar profundamente errado em meu posicionamento. Somente a discussão franca e honesta dos pontos de vista conflitantes poderá levar a avanços nessa área.

"Discussões exaustivas de métodos, informaçōes exaustivas de processos, troca de opiniōes sobre tudo, eis a única forma possivel de esclarecer teorias e melhorar o nivel da prática. A discussāo, mesmo quando não traz a luz, liquida com muita idéia imbecil".

Millôr Fernandes

\section{REFERENCIAS}

1 ALMEIDA, Guido de. 1989. Resgatando a contribuição da sociolinguiística laboviana. D.E.L.T.A., Sāo Paulo, v.5, n.1, p.71-99, 1989.

2 AYER, A.J. (comp.) 1959 |1986|. El Positivismo Lógico. México: Fondo de Cultura Economica.

3 BOHM, David. 1979. Ia ciencia como percepción-communicación. In SUPPE, F. La estructura de las teorias cientificas. Madri: Ed. Nacional, 1979, pp. 421-439.

4 BORER, Hagit. 1981. Parametric variation in clitic constructions. M.I.T., PhD. Dissertation.

5 BORGES NETO, J. 1985. Díalogo sobre as razöes da diversidade teórica na Lingiiistica. Fragmenta Linguistica \& Literaria, Curitiba, n.2, p.1-13.

6 1987. Filosolia da Lingüística. Texto lido durante a $39 .^{\circ}$ Reuniz̄o Anual da SBPC (Brasilia, 1987). Manuscrito inédito. 

; MULLLER, Ana Lúcia. 1987. Linguiistas ou camaleōes? uma resposta a Tarallo. D.E.L.T.A., São Paulo, v.3, n.1, p.85-95, 1987.

8 BORTONI-RICARDO, Stella Maris. 1985. The urbanization of rural dialect speakers. Cambridge University Press.

9 CEDERGREN, H. \& SANKOFF, D. 1974. Variable rules: performance as a statistical reflection of competence. Language v.50, n.2, p.333-355.

10 CHOMSKY, Noam. 1986. Knowledge of Language. Nova Iorque: Praeger.

11 DITTMAR, Norbert. 1976. Sociolingulstics: a critical survey of theory and application. Londres: Edward Arnold.

12 FEYERABEND, Paul. 1977. Contra o Método. Rio: Francisco Alves.

14 HAWKING, Stephen. 1988. Uma breve história do tempo: do Big Bang aos buracos negros. Rio: Rocco.

14 KUHN, Thomas. 1962 |1975|. A estrutura das revoluçōes cientificas. São Paulo: Perspectiva.

$15-1970$ |1975|. Consideración en torno a mis críticos. In LAKATOS, I.; MUSGRAVE, A. (eds.) La crítica y el desarrollo del conocimiento. Barcelona: Grijalbo.

16 LABOV, W. 1972. Sociolinguistic patterns. Filadelfia: University of Pennsylvania Press.

17 1981. Resolving the neogrammarian controversy Language v.57, n.2, p.267-308, 1981.

18 1982. Building on empirical foundations. In LEHMANN, W.; MALKIEL, Y. (eds.) Perspectives on historical linguistics. Amsterdan: John Benjamins, 1982, pp. 17-92.

19 MILROY, Lesley. 1980. Language and social networks. Oxford: Basil Blackwell.

20 NEURATH, Otto. 1959a. Proposiciones protocolares. In: AYER (comp.) 1959, p.205-214.

$21-1959 \mathrm{~b}$. Sociologia en fisicalismo. In: AYER (comp.) 1959, p.287-322.

22 OLIVEIRA, Marco Antonio de. 1986. Algumas notas sobre o conceito de variável lingüística e sua dimensão nas descriçōes gramaticais. ABRALIN: Boletim da Associação Brasileira de Lingüística n.8, p.87-95, 1986 .

23 1987. Variável lingüistica: conceituaçăo, problemas de descrição gramatical e implicações para a construção de uma teo. ria gramatical. D.E.L.T.A., Sāo Paulo, v.3, n.1, p.19-34, 1987.

24 RAJAGOPALAN, Kanavillil. 1988. Evidências e argumentos: reflexões sobre a construção de teorias lingüísticas. Texto lido durante a $40{ }^{\mathrm{a}}$ Reuniăo Anual da SBPC (São Paulo, 1988). Manuscrito inédito.

25 SANKOFF, G.; TARALLO, F. 1987. Relativization and anaphora in spoken language. D.E.L.T.A., São Paulo, v.3, n.2, p.197-214, 1987. 
NETO. J.B. A Incomensursbllidade $e$ " "compatibllizacto"

26 SAUSSURE, Ferdinand de. $1916|1970|$. Curso de Lingüistica Geral. Sāo Paulo: Cultrix, 1970.

27 TARALLO, Fernando. 1986a. Zelig: um camaleão-lingüista. D.E.L.T.A., São Paulo, v.2, n.1, p.127-144, 1986.

28 1986b. "Era uma vez...": Estória, História e Ahistória. O Histórico e o Discursivo, Uberaba: FIUBE (série Estudos n.' 12).

29 1987. Por uma sociolinguistica românica "paramétrica": fonologia e sintaxe. Ensaios de Lingüistica, Belo Horizonte, n.13, p.51.83, 1987.

30 WHORF, Benjamin L. 1956. Language, Thought and Reality. Cambridge, Mass.: MTT Press. 